\title{
Cardiothoracic Area Ratio Predicts Lethal Pulmonary Venous Obstruction in Patients with Single Ventricle and Total Anomalous Pulmonary Venous Connection
}

\author{
Misugi Emi, MD ${ }^{1}$ Noboru Inamura, MD, $\mathrm{PhD}^{2}$ \\ ${ }^{1}$ Department of Pediatric Cardiology, Osaka Medical Center and \\ Research Institute for Maternal and Child Health, Izumi, Osaka, Japan \\ 2 Kinki Daigaku Igakubu Daigakuin Igaku Kenkyuka, Osakasayama, \\ Osaka, Japan
}

\begin{abstract}
Address for correspondence Misugi Emi, MD, Department of Pediatric Cardiology, Osaka Medical Center and Research Institute for Maternal and Child Health, 840 Murodo-cho, Izumi, Osaka 594-1101, Japan (e-mail: emi1108@mch.pref.osaka.jp).
\end{abstract}

Am J Perinatol Rep 2018;8:e174-e179.

\begin{abstract}
Background and Objectives When single ventricle (SV) is complicated with total anomalous pulmonary venous connection (TAPVC), the pulmonary vein obstruction (PVO) occurs at a high rate.

There are some patients who died from the lethal PVO (I-PVO) which needed PVO release dead due to severe desaturation within 24 hours after birth. The purpose of this study was to find a predictive marker for I-PVO during the fetal period.

Methods We enrolled 21 patients diagnosed with SV associated with TAPVC in the antenatal period. Ten patients had supracardiac, five had cardiac, five had infracardiac, and one had mixed TAPVC. We reviewed fetal echocardiography and measured cardiothoracic area ratio (CTAR) and total cardiac dimension (TCD). We divided 21

Keywords

- pulmonary venous obstruction

- single ventricle

- TAPVC

- Fetal echocardiography

- CTAR cases into I-PVO group (6) and non-I-PVO group (15) and compared the fetal echocardiography findings and postnatal prognoses between the groups.

Results CTAR at the final fetal echocardiography was 16 to $29 \%$ (median: 21 ) in the IPVO group and 22 to $38 \%$ (median: 28 ) in the non-I-PVO group ( $p=0.01)$. TCD/week at the final echocardiography was 0.67 to 1.0 (median: 0.77 ) in the I-PVO group and 0.78 to 1.2 (median: 0.96$)$ in the non-I-PVO group $(p=0.02)$.

Conclusion Reduced CTAR in the antenatal period is a good predictor of I-PVO after birth.
\end{abstract}

Some patients with single ventricle (SV) associated with total anomalous pulmonary venous connection (TAPVC) and pulmonary venous obstruction (PVO) die immediately after birth. ${ }^{1-5}$ If these cases can be picked up during the antenatal period, more time can become available for the appropriate planning of treatment after birth and explanation to their parents. Pulmonary venous velocity or flow pattern according to fetal echocardiography had been used to predict these issues. ${ }^{6-13}$ However, in clinical practice, more severe PVO is more difficult to identify. Therefore, we aimed to identify the other predictors of lethal PVO (1-PVO) in fetuses with SV.

received

December 20, 2017 accepted after revision March 14, 2018
DOI https://doi.org/

10.1055/s-0038-1669429. ISSN 2157-6998.

\section{Methods}

Between 2005 and 2015, 21 patients who were diagnosed with SV and TAPVC by fetal echocardiography at our institute were identified. The mothers underwent fetal echocardiography at the Osaka Medical Center and Research Institute for Maternal and Child Health, Izumi, Osaka, Japan. Pre- and postnatal medical records were reviewed to obtain data on clinical parameters, including perinatal outcomes.

We defined l-PVO as the need for PVO treatment within 24 hours after birth or the inability to perform surgery due to severe desaturation or bad general health of the neonate. Six

Copyright @ 2018 by Thieme Medical Publishers, Inc., 333 Seventh Avenue, New York, NY 10001, USA. Tel: +1(212) 584-4662.
License terms

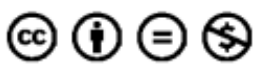


patients had l-PVO. The remaining 15 patients had nonlethal PVO (non-l-PVO).

\section{Fetal Echocardiography}

Fetal echocardiography with cardiovascular anatomical assessment was performed according to previously described techniques using a variety of echocardiography systems. All images were recorded on DVDs for offline analysis. Three investigators reviewed all fetal echocardiographic findings. The following dimensions were defined: cardiothoracic area ratio (CTAR) and total cardiac dimension (TCD) (-Fig. 1). For analysis, we used the values of CTAR, $T C D$, and Tei index obtained at the final fetal echocardiography, which was performed at gestational age of 34 to 38 weeks (median: 36 weeks). We calculated the combined cardiac output (CCO) of the 6 cases with pulmonary atresia. Three representative heart cycles were traced for the measurement of velocity time integral (VTI). CCO is calculated by using the formula, $\mathrm{CCO}=\pi(\text { aortic diameter }(\mathrm{cm}) / 2)^{2} \times$ VTI $(\mathrm{cm}) \times$ heart rate $(\mathrm{bpm}) /$ estimated body weight $(\mathrm{kg})$, and the average value was recorded. And we compared CTAR, TCD, Tei index, and CCO between cases with l-PVO and non-l-PVO.

\section{Statistical Analysis}

Comparisons between groups were performed using the Mann-Whitney $U$ test.

A $p$-value of $<0.05$ was considered statistically significant. The differences between the assessments of the investigators were assessed using interclass correlation coefficients (ICCs).

\section{Results}

\section{Patient Profiles}

We summarized the 21 patients in - Table 1. Six of the 21 patients suffered from l-PVO. Analysis of the atrial situs revealed that 19 patients had right isomerism (RI); all of the patients with 1-PVO had RI. Ten patients had supracardiac TAPVC, five had cardiac TAPVC, five had infracardiac TAPVC, and one had mixed TAPVC. Regurgitation of the atrioventricular valves was more than mild in eight fetuses (1-PVO: 2 , nonl-PVO: 6). Body weight at birth was 1,788 to $4,126 \mathrm{~g}$ (median: $2,692 \mathrm{~g}$ ). Five patients required intubation and mechanical ventilator soon after birth, four of whom were in the l-PVO group. All of the four patients who suffered from pneumothorax after birth had 1-PVO, while none of the non-1PVO patients had pneumothorax. Surgery was performed in four of the six patients with l-PVO within 24 hours after birth and two of the four patients died at the 168th and 199th day.

\section{Fetal Echocardiographic Findings}

We performed fetal echocardiography multiple times between 22 and 38 weeks of gestation. The final fetal echocardiography was performed at 34 to 38 weeks (median: 36.2 weeks). - Fig. 1 shows the method used to measure cardiac size: the ellipse method. - Table 2 shows the correlations between echocardiographic findings and prognoses. CTAR in the l-PVO group was significantly lower than that in the non-l-PVO group (16-29\% [median: $21 \%$ ] vs. $22-38 \%$ [median: $28 \%$ ], $p=0.01$ ). TCD/week in the l-PVO group was significantly lower than that in the non-l-PVO group (0.67-1.0 [median: 0.77] vs. 0.78-1.2 [median: 0.96], $p=0.02)$. Tei index in the l-PVO group was lower than that in the non-l-PVO group (0.26-0.34 [median: $0.30 \%$ ] vs. $0.28-0.48 \%$ [median: $0.40 \%$ ], $p=0.02$ ). The values of CTAR, TCD/week, and Tei index were significantly lower in the lPVO group than those in the non-l-PVO group. We were able to calculate the $\mathrm{CCO}$ in six patients with pulmonary atresia (1PVO: 2 [cases 16, 21]; non-l-PVO: 4 [cases 2, 3, 4, 8]). The values were 183 and $250 \mathrm{~mL} / \mathrm{kg}$ in the l-PVO group and 308 to $589 \mathrm{~mL} / \mathrm{kg}$ in the non-l-PVO group (-Fig. 2).

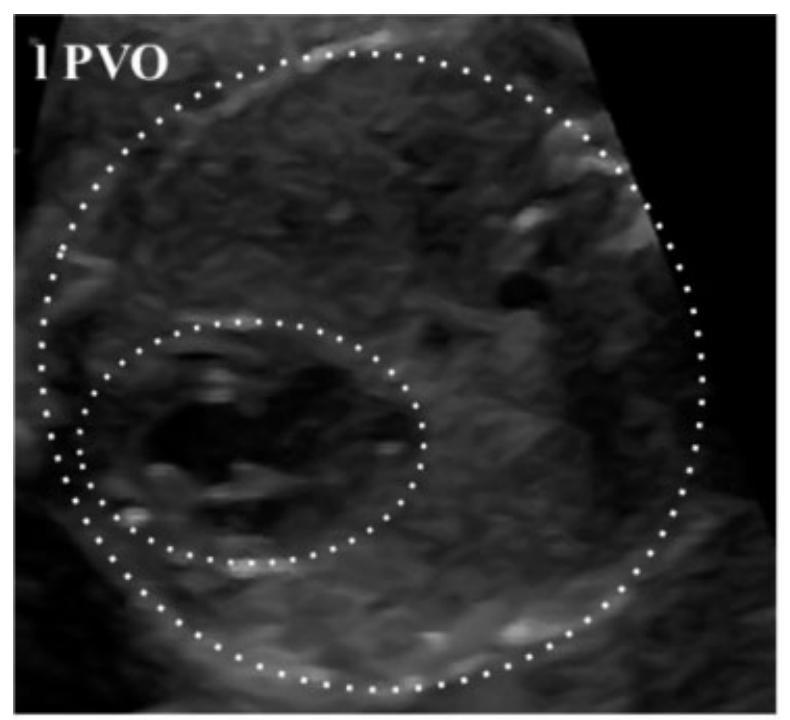

CTAR: $17.9 \%$

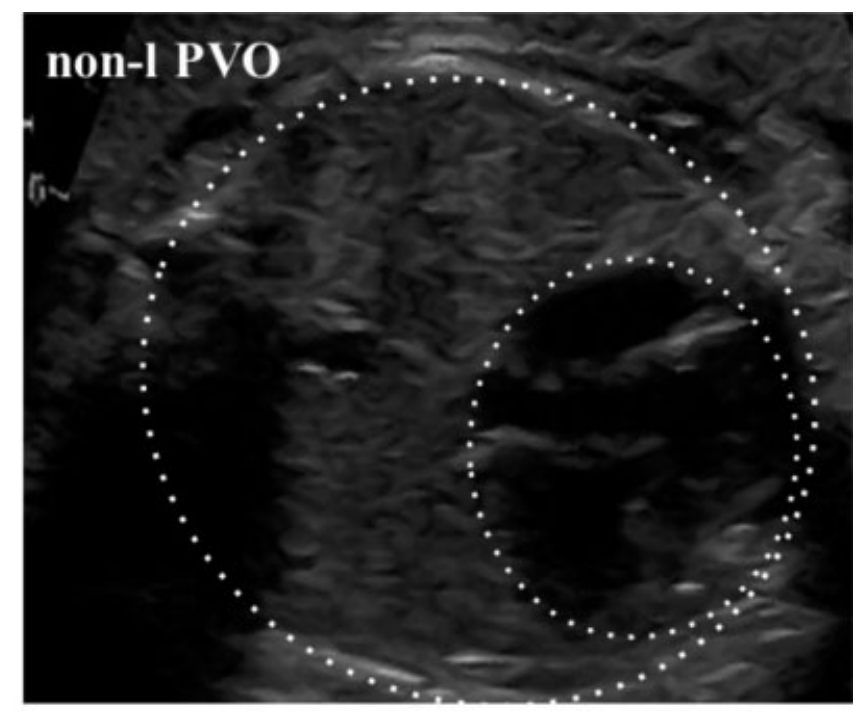

CTAR: $31.2 \%$

Fig. 1 Procedure for measuring cardio-thoracic area ratio. 


\begin{tabular}{|c|c|c|c|c|c|c|c|c|c|c|c|c|c|c|c|c|c|c|c|c|c|c|}
\hline 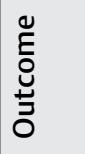 & 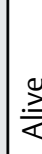 & $\stackrel{\stackrel{u}{z}}{\frac{2}{4}}$ & $\mid \stackrel{\Xi}{\ddot{\varepsilon}}$ & 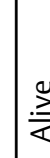 & $\stackrel{3}{\frac{3}{4}}$ & 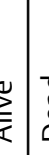 & 苞 & \begin{tabular}{|l|}
$\vec{J}$ \\
$\tilde{\Xi}$ \\
0
\end{tabular} & $\begin{array}{l}\tilde{\Xi} \\
\tilde{\Xi} \\
0\end{array}$ & 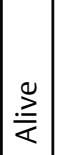 & 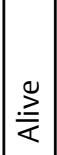 & 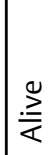 & $\begin{array}{l}\tilde{\Xi} \\
\tilde{\Xi} \\
0\end{array}$ & 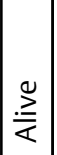 & 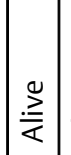 & 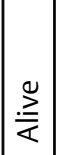 & $\mid \begin{array}{l}\mathscr{J} \\
\stackrel{\Xi}{\Delta} \\
0\end{array}$ & 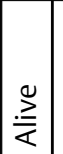 & \begin{tabular}{|l|}
$\tilde{\mathbb{Z}}$ \\
$\tilde{\mathbb{I}}$
\end{tabular} & 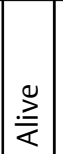 & 离 & \begin{tabular}{|l}
$\widetilde{J}$ \\
$\tilde{\Xi}$
\end{tabular} \\
\hline 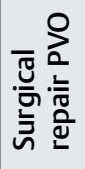 & $\frac{0}{2}$ & $\begin{array}{l}\bar{N} \\
\text { తo } \\
0\end{array}$ & $\mid \begin{array}{l}\text { m } \\
\stackrel{\varpi}{0}\end{array}$ & $\mid \begin{array}{l}8 \\
8 \\
0\end{array}$ & 家 & $\begin{array}{l}5 \\
\overline{5} \\
\overline{5}\end{array}$ & 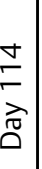 & 일 & $\begin{array}{l}\stackrel{\omega}{N} \\
\vec{\pi} \\
0\end{array}$ & 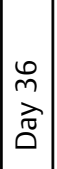 & 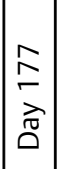 & $\frac{0}{2}$ & $\frac{0}{2}$ & 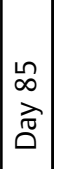 & 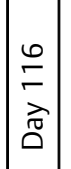 & 2 & f & \begin{tabular}{|l|}
\multicolumn{1}{|c|}{} \\
\end{tabular} & $\frac{1}{\infty}$ & $\begin{array}{ll}r \\
m\end{array}$ & 2 & 2 \\
\hline 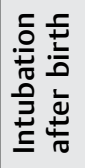 & $\frac{0}{z}$ & 울 & z & $\frac{0}{z}$ & $\frac{c}{z}$ & & $\frac{1}{z}$ & $\stackrel{\tilde{y}}{\succ}$ & z & z & $\frac{0}{z}$ & $\frac{0}{z}$ & $\frac{0}{z}$ & z & z & z & $\stackrel{\tilde{u}}{\succ}$ & $\stackrel{\tilde{u}}{\check{\nu}}$ & $\stackrel{\tilde{u}}{\rightleftharpoons}$ & in & $\stackrel{\check{\nu}}{\varnothing}$ & $\stackrel{\check{\mu}}{\rightleftharpoons}$ \\
\hline 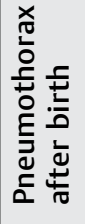 & z & ? & z & z & $\frac{c}{2}$ & & i & 1 & z & \& & z & $\frac{0}{z}$ & z & i & z & z & z & i & $\stackrel{\tilde{u}}{\succ}$ & 2 & $\stackrel{\check{\nu}}{\check{\nu}}$ & $\stackrel{\check{\nu}}{\succ}$ \\
\hline 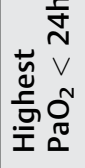 & $\frac{1}{\dot{\gamma}}$ & $\stackrel{m}{\stackrel{m}{m}}$ & $\underset{f}{J}$ & $\begin{array}{l}\vec{J} \\
\text { ڤn }\end{array}$ & $\stackrel{\sim}{\sim}$ & $?$ & $\begin{array}{l}0 \\
\dot{y} \\
\gamma\end{array}$ & 1 & $\begin{array}{l}\mathfrak{r} \\
\dot{b} \\
m\end{array}$ & $\mid \begin{array}{l}m \\
\dot{\sigma} \\
\end{array}$ & $\mid \begin{array}{l}\infty \\
\stackrel{\dot{f}}{*}\end{array}$ & $\stackrel{m}{\tilde{q}}$ & $\mid \begin{array}{l}n \\
\dot{0} \\
\dot{0}\end{array}$ & $\begin{array}{l}\infty \\
\tilde{\gamma} \\
\dot{\gamma}\end{array}$ & $\mid \begin{array}{l}n \\
\infty \\
\infty \\
\sigma\end{array}$ & $\mid \begin{array}{c}m \\
\dot{f} \\
\end{array}$ & $\mid \begin{array}{l}\mid \\
\dot{\gamma} \\
\end{array}$ & 1 & $\begin{array}{l}\dot{0} \\
\dot{m}\end{array}$ & $\mid \begin{array}{l}\infty \\
\infty \\
\infty \\
\sim\end{array}$ & $\stackrel{\sim}{\stackrel{\sim}{\sim}}$ & $\begin{array}{l}\infty \\
\stackrel{m}{m}\end{array}$ \\
\hline 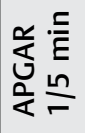 & $\frac{\infty}{\infty}$ & $\frac{\infty}{\infty}$ & $\frac{7}{\rho}$ & $\frac{\infty}{\infty}$ & $\stackrel{\infty}{\lambda}$ & & $\frac{\infty}{\infty}$ & I & $\frac{N}{N}$ & $\frac{\infty}{r}$ & $\frac{\infty}{\infty}$ & $\frac{\infty}{\infty}$ & $\frac{a}{\infty}$ & $\frac{\infty}{\infty}$ & $\frac{\infty}{\infty}$ & $\frac{\infty}{\infty}$ & $\frac{a}{\infty}$ & $\frac{\infty}{\wedge}$ & $\frac{N}{r}$ & $\frac{\infty}{\infty}$ & $\frac{n}{m}$ & $\frac{n}{n}$ \\
\hline
\end{tabular}

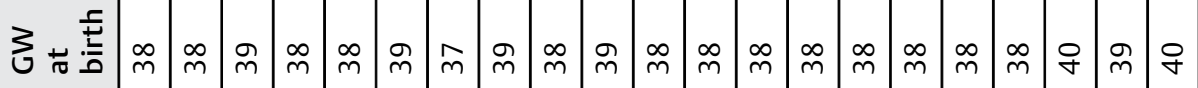

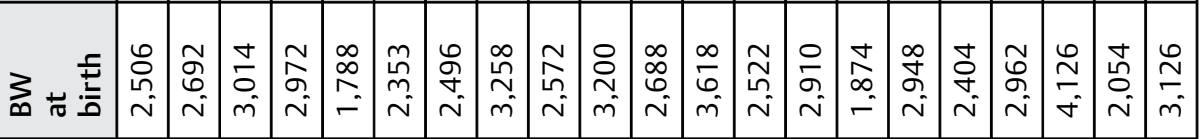

\begin{tabular}{|c|c|c|c|c|c|c|c|c|c|c|c|c|c|c|c|c|c|c|c|c|}
\hline 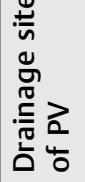 & 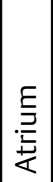 & $\stackrel{s}{\sim}$ & 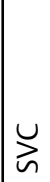 & $\begin{array}{l}> \\
\underline{\underline{E}}\end{array}$ & $\stackrel{u}{n}$ & $\mid \begin{array}{l}> \\
\underline{\underline{E}}\end{array}$ & $\frac{\geq}{3}$ & \begin{tabular}{|l|}
$\frac{3}{\pi}$ \\
$\frac{\pi}{0}$ \\
2 \\
2
\end{tabular} & $\begin{array}{l}\geq \\
\frac{\pi}{\pi} \\
0 \\
0\end{array}$ & $\underset{\backsim}{\longleftarrow}$ & 苞 & 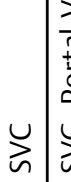 & 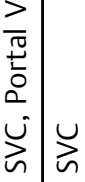 & 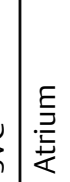 & 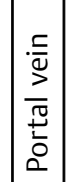 & 至 & $=$ & & 至 & $\underset{\sim}{\longleftarrow}$ \\
\hline
\end{tabular}

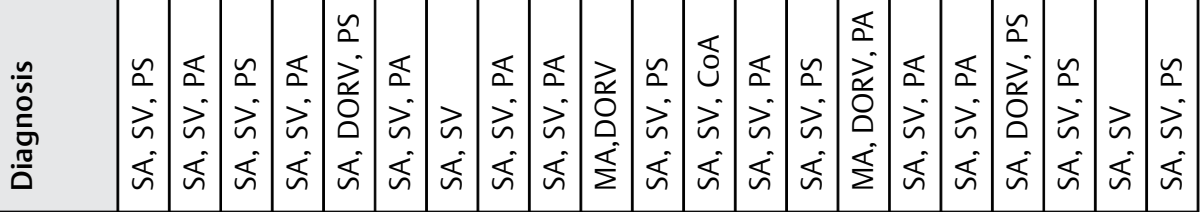

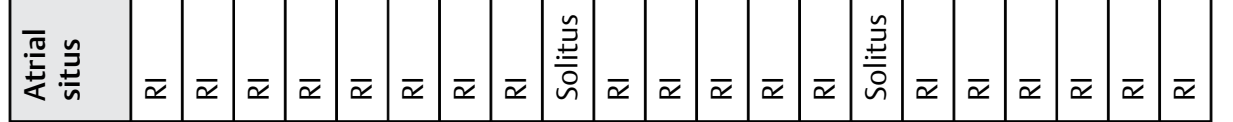

\begin{tabular}{|c|c|c|c|c|c|c|c|c|c|c|c|c|c|c|c|c|c|c|c|}
\hline$\sum_{0}$ & $\stackrel{\sim}{\sim}$ & $\stackrel{\llcorner}{\sim}$ & $\stackrel{\stackrel{2}{N}}{\sim}$ & 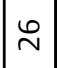 & 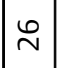 & શ & શ & શ) & શ & શิ & $\stackrel{n}{m} \tilde{m}$ & $\begin{array}{l}m \\
m\end{array}$ & mे & $\stackrel{\llcorner}{m}$ & $\stackrel{ }{ }$ & $\approx$ & $\approx$ & $\stackrel{\sim}{\sim}$ & $v)$ \\
\hline مج & z & ì & z & $\frac{0}{2}$ & z & 2) & 2 & $\frac{0}{z}$ & $\frac{2}{2}$ & $\begin{array}{l}2 \\
2\end{array}$ & \begin{tabular}{l|l}
2 \\
$z$
\end{tabular} & $\frac{0}{2}$ & 2 & $\stackrel{0}{z}$ & $\stackrel{\tilde{\nu}}{>}$ & $\stackrel{\tilde{c}}{\succ}$ & 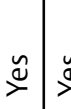 & 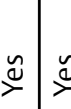 & $\underline{\hat{y}} \bar{y}$ \\
\hline 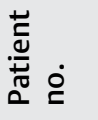 & - & $\sim$ & $m$ & $\nabla$ & in & 6 & $r$ & $\infty$ & $a$ & $\therefore 7$ & $F$ & $=m$ & $\Xi$ & $\stackrel{\text { ㅁ }}{\leftarrow}$ & $\stackrel{6}{\square}$ & 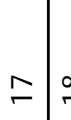 & $\stackrel{\infty}{\square}$ & ๑ & $\vec{v} \mid \bar{n}$ \\
\hline
\end{tabular}


Table 2 Summary of fetal echocardiography before birth (mean \pm SD)

\begin{tabular}{|l|l|l|l|l|l|}
\hline & Gestational wk & TCD/GW & CTAR (\%) & Tei index & CAVVR (mild) \\
\hline Critical PVO (+) & $38.5(38-40)$ & $\begin{array}{l}0.77 \pm 0.13 \\
(0.67-1.0)\end{array}$ & $21 \pm 4.7(16-29)$ & $\begin{array}{l}0.30 \pm 0.040 \\
(0.26-0.34)\end{array}$ & $6 / 15$ \\
\hline Critical PVO (-) & $38(37-39)$ & $\begin{array}{l}0.96 \pm 0.097 \\
(0.78-1.2)\end{array}$ & $28 \pm 4.2(22-38)$ & $\begin{array}{l}0.40 \pm 0.072 \\
(0.28-0.48)\end{array}$ & $2 / 6$ \\
\hline P PVO (+) vs. PVO (-) & NS & $p=0.02$ & $p=0.01$ & $p=0.02$ & \\
\hline
\end{tabular}

Abbreviations: CAVVR, common atrioventricular valve regurgitation; CTAR, cardiothoracic area ratio; $G W$, gestational week; PVO, pulmonary venous obstruction; SD, standard deviation; TCD, total cardiac dimension.

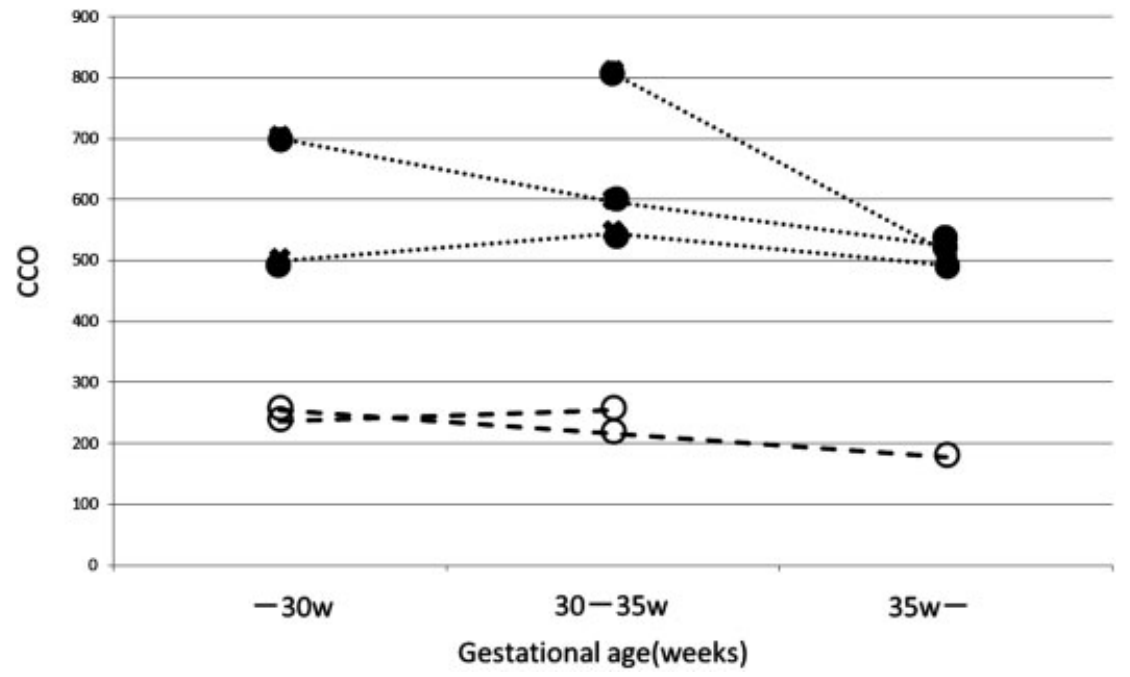

Fig. 2 Changes in cardio-thoracic area ratio (CTAR) by gestational week. The open circle shows the change in patients with lethal pulmonary vein obstruction (I-PVO). The closed circle shows the change in non-I-PVO patients. CTAR gradually decreased in cases of I-PVO with no or trivial regurgitation of the atrioventricular valve.

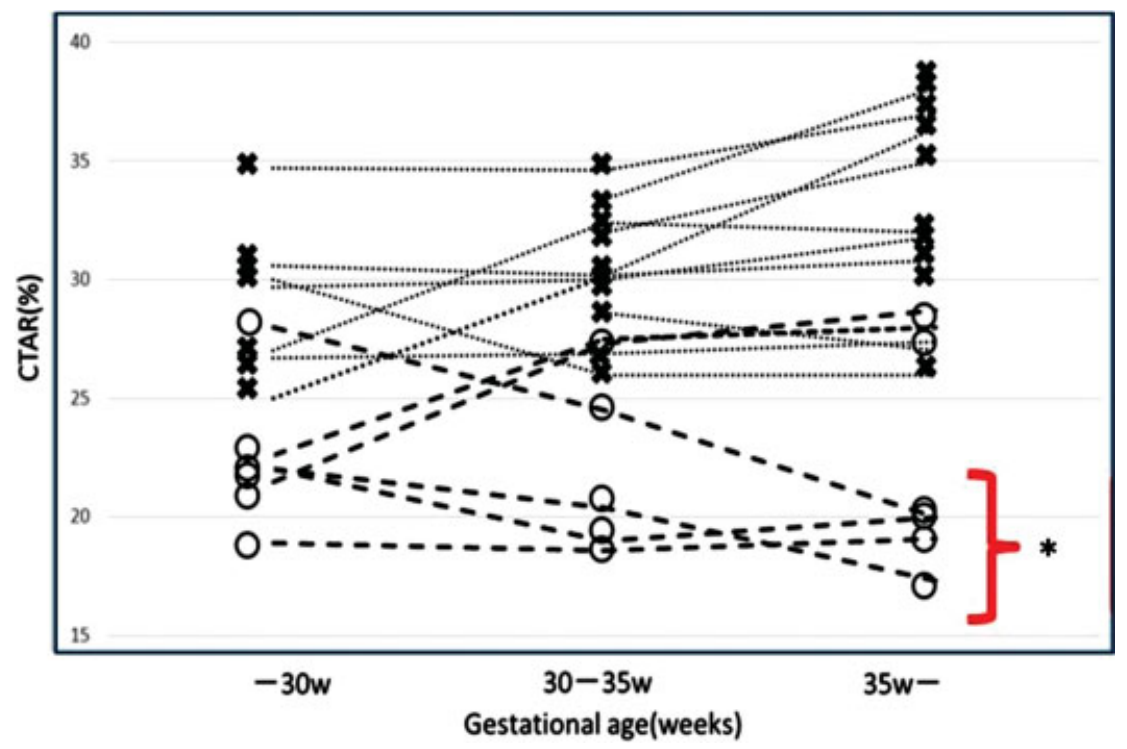

Fig. 3 Changes in combined cardiac output by gestational week showing the CCO of patients with lethal pulmonary vein obstruction (I-PVO) and non-I-PVO with single ventricle, total anomalous pulmonary venous connection, and pulmonary atresia. The open circle shows the CCO of patients with I-PVO. The closed circle shows the CCO of patients with non-I-PVO. CCO; combined cardiac output. 


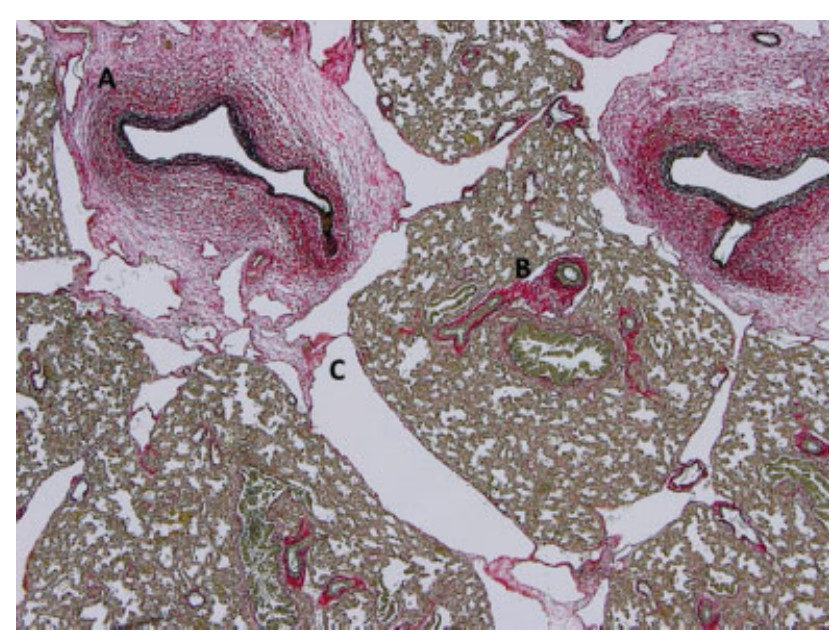

Fig. 4 Histological findings from a lung sample from case 20 (who died 16 hours after birth due to pulmonary vein obstruction). (A) The elastic fiber is hypertrophic, especially in the pulmonary vein. (B) The media of the pulmonary artery is hypertrophic. Heath-Edwards grade $=I$. (C) The interstitial wall of the pulmonary alveolus is hypertrophic and the lymphatic vessels are dilated. (D) The wall of the pulmonary alveolus is edematous and there are many cellular components and thickening.

\section{Difference between Observers}

Three investigators measured the CTAR and TCD based on reviews of findings. For CTAR, the median ICC was 0.88 and the single measures ICC was $0.70(p<0.01)$. For TCD, the median ICC was 0.93 and the single measures ICC was 0.82 $(p<0.01)$.

\section{Discussion}

The results of this study demonstrated that l-PVO after birth is associated with respiratory failure and pneumothorax. If patients with l-PVO are not diagnosed antenatally, the risk of death increases. If these cases can be identified before birth, it will be possible to prepare treatment strategies and inform their parents about the clinical situation. However, it is difficult to diagnose disorders of the pulmonary vein in the antenatal period, and diagnosis of PVO is particularly challenging. ${ }^{10,14}$ In this study, we failed to diagnose TAPVC in 3 of 21 cases. Furthermore, we could diagnose l-PVO in just two of six patients antenatally. Diagnosis is thought to be difficult because pulmonary blood flow decreases in cases of fetal PVO. ${ }^{7,9,13}$ Fetal pulmonary blood flow is important for the development of appropriate fetal heart preload in the latter half of the pregnancy. ${ }^{15}$ The heart most probably remains small because preload decreases in fetuses with PVO.

The lower values of CTAR can suggest SV and TAPVC associated with 1-PVO. The changes in CTAR in the antenatal period observed in this study are shown in - Fig. 3. The CTAR values of patients with l-PVO were lower than those of patients with non-1-PVO. In particular, in the case of no or trivial regurgitation of the atrioventricular valve, the value of CTAR became smaller at any time. In these cases, the cut-off value of CTAR was $22.7 \%$ (sensitivity $=100 \%$, specificity $=100 \%$ ). The CTAR value was lower in the l-PVO group and appeared to represent a good index to predict 1-PVO.

We measured the CCO to make sure that the CTAR with l-PVO is smaller. We compared the difference in CCO between the l-PVO and non-l-PVO groups. The CCO in the 1-PVO group was lower than that in the non-l-PVO group. These results suggest that pulmonary blood flow volume in patients with 1-PVO decreased due to PVO and that heart preload more severely decreased in lethal cases. According to Moss and Adams', which is one of the most common textbooks for pediatric cardiology, the decreased inflow from the left atrial leads to decrease in left ventricular volume in the cases of TAPVC with PVO. Finally, they show that the heart size in the l-PVO group decreased and the value of CTAR got smaller.

The cases of the l-PVO group often suffered from pneumothorax and it is sometimes the cause of death. - Fig. 4 shows the histological findings from lung samples from case 20 , a patient who died 16 hours after birth due to l-PVO. The findings showed that the elastic fiber is hypertrophic, especially in the pulmonary vein, that the media of the pulmonary artery is hypertrophic, and that the interstitial wall of the pulmonary alveolus is hypertrophic and the lymphatic vessels are dilated.

It means that the lumen of the pulmonary artery and vein was narrower. Moss and Adams' also showed similar findings of the pulmonary vein and lungs due to PVO.

Therefore, we conclude lower preload due to a narrower lung vessel lumen and more severe lung edema contribute to the lower values of CTAR with l-PVO.

\section{Study Limitation}

This study has several limitations that should be discussed. First, the number of cases was small, and so the cut-off value for CTAR may be changed. Second, we calculated the CCO in only six cases of pulmonary atresia because the value was not correct due to the fast flow velocity in the cases with pulmonary stenosis. Because of the small sample volume, the data of the CCO may be changed.

In conclusion, in patients with 1-PVO of SV and TAPVC, the symptom rerated to PVO rapidly progresses postnatally due to decrease in pulmonary blood flow. The antenatal values of CTAR are lower in patients with l-PVO. Thus, CTAR serves as a good predictor of 1-PVO associated with SV and TAPVC.

\section{References}

1 Sadiq M, Stümper O, De Giovanni JV, et al. Management and outcome of infants and children with right atrial isomerism. Heart 1996;75(03):314-319

2 Talwar S, Agarwal P, Choudhary SK, Airan B. Functionally univentricular heart with right atrial isomerism and mixed total anomalous pulmonary venous drainage. World J Pediatr Congenit Heart Surg 2016;7(03):377-380

3 Khan MS, Bryant R III, Kim SH, et al. Contemporary outcomes of surgical repair of total anomalous pulmonary venous connection in patients with heterotaxy syndrome. Ann Thorac Surg 2015;99 (06):2134-2139, discussion 2139-2140 
4 Nakata T, Fujimoto Y, Hirose K, et al. Functional single ventricle with extracardiac total anomalous pulmonary venous connection. Eur J Cardiothorac Surg 2009;36(01):49-56, discussion 56

5 Hoashi T, Kagisaki K, Oda T, et al. Long-term results of treatments for functional single ventricle associated with extracardiac type total anomalous pulmonary venous connection. Eur J Cardiothorac Surg 2013;43(05):965-970

6 Hashmi A, Abu-Sulaiman R, McCrindle BW, Smallhorn JF, Williams WG, Freedom RM. Management and outcomes of right atrial isomerism: a 26-year experience. J Am Coll Cardiol 1998;31(05): 1120-1126

7 DiSessa TG, Emerson DS, Felker RE, Brown DL, Cartier MS, Becker JA. Anomalous systemic and pulmonary venous pathways diagnosed in utero by ultrasound. J Ultrasound Med 1990;9(06): 311-317

8 Colloridi V, Pizzuto F, Ventriglia F, Giancotti A, Pachì A, Gallo P. Prenatal echocardiographic diagnosis of right atrial isomerism. Prenat Diagn 1994;14(04):299-302

9 Patel CR, Lane JR, Spector ML, Smith PC, Crane SS. Totally anomalous pulmonary venous connection and complex congenital heart disease: prenatal echocardiographic diagnosis and prognosis. J Ultrasound Med 2005;24(09):1191-1198
10 Feller Printz B, Allan LD. Abnormal pulmonary venous return diagnosed prenatally by pulsed Doppler flow imaging. Ultrasound Obstet Gynecol 1997;9(05):347-349

11 Patel CR, Lane JR, Muise KL. In utero diagnosis of obstructed supracardiac total anomalous pulmonary venous connection in a patient with right atrial isomerism and asplenia. Ultrasound Obstet Gynecol 2001;17(03):268-271

12 Valsangiacomo ER, Hornberger LK, Barrea C, Smallhorn JF, Yoo SJ. Partial and total anomalous pulmonary venous connection in the fetus: two-dimensional and Doppler echocardiographic findings. Ultrasound Obstet Gynecol 2003;22(03):257-263

13 Volpe P, Campobasso G, De Robertis V, et al. Two- and fourdimensional echocardiography with B-flow imaging and spatiotemporal image correlation in prenatal diagnosis of isolated total anomalous pulmonary venous connection. Ultrasound Obstet Gynecol 2007;30(06):830-837

14 Papa M, Camesasca C, Santoro F, et al. Fetal echocardiography in detecting anomalous pulmonary venous connection: four false positive cases. Br Heart J 1995;73(04):355-358

15 Allan LD, Sharland GK. The echocardiographic diagnosis of totally anomalous pulmonary venous connection in the fetus. Heart 2001;85(04):433-437 